\title{
Semi-Automatic Detection of Storm-Felled Forest Areas in Western Norway's Spruce Forests Using a Landsat Time Series and Change Detection
}

\author{
Johannes May \\ University of Sustainable Development Eberswalde, Germany · johannes.may87@gmail.com
}

Full paper double blind review

\begin{abstract}
Within the widely investigated field of forest disturbance monitoring, the detection of forest storm damages with remote sensing techniques gained rather low attention in the last years. This work aims to fill this gap. The project of storm damage detection, focusing on spruce forests, was initiated by the Norwegian Forest and Landscape Institute 'Skog og Landskap'. The triggering event for this investigation was the storm 'Dagmar' from December 2011. This storm event and its impact on spruce forests on Norway's west coast are investigated to develop a semi-automatic storm damage detection model. For detecting storm damages, primarily the question of adequate data pre-processing of Landsat 7 ETM+ is discussed. In the pre-processing stage, haze reduction, image-to-image registration, atmospheric and topographic correction are applied. The 'Wide Dynamic Range Vegetation Index' (WDRVI) is analysed and evaluated for its applicability when detecting forest storm damages. Pixel information from known storm areas is extracted, and compared with a focus on data distribution and the trend behaviour for different damage categories. A correlation was detected between the data trend of the WDRVI and the increasing damage percentages in the forest, showing an increase in WDRVI values for increasing damage percentages in the observed forest stands. Therefore, the WDRVI provides the best possibilities to detect storm damages in the study area. Through a non-linear regression analysis and 'Partitioning Around Medoids' classification (PAM), thresholds are derived from the WDRVI change image. Implementing those thresholds in an ERDAS 2013 spatial model, a tool is developed, which detects forest changes without the requirement of further user input. The only requirements are pre-processed Landsat 7 images before and after the storm, and a defined area of interest data (AOI), e.g. a vector-mask of spruce forests. Testing and evaluating the semiautomatic detection model on a larger AOI (covering almost a whole Landsat 7 scene) achieved an overall accuracy of $96.3 \%$ (Cohen's KAPPA of 0.94 ). With very good detection results, this investigation contributes to forest management and a faster response to storm damaged forest areas.
\end{abstract}

\section{Introduction}

With emphasis on forest damages caused by storm events, the research progress is rather low compared to insect infestation and forest fire monitoring (KING et al. 2005, BAUMANN

GI_Forum - Journal for Geographic Information Science, 1-2015.

(c) Herbert Wichmann Verlag, VDE VERLAG GMBH, Berlin/Offenbach. ISBN 978-3-87907-558-4.

(C) ÖAW Verlag, Wien. ISSN 2308-1708, doi:10.1553/giscience2015s117. 
et al. 2013). To contribute in this specific field of forest disturbance monitoring (CARVALHO et al. 2004, LAUSCH et al. 2013, PRADHAN et al. 2007), this study investigates stormdamaged forests, classifies different damage severities, and aims to develop a semi automated detection model.

The study area was situated on Norway's west coast, more specifically including areas around Sogne- and Nordfjord. Geographically its location was between $62^{\circ} 10^{\prime} \mathrm{N}$ and $61^{\circ} 30^{\prime} \mathrm{N}, 5^{\circ} 40^{\prime} \mathrm{E}$ and $6^{\circ} 50^{\prime} \mathrm{E}$, and covered an area of 686000 ha. The included mountains range from $90 \mathrm{~m}$ to $460 \mathrm{~m}$ above sea level in altitude, with slope inclinations between $5^{\circ}$ and $45^{\circ}$, orientated in all directions $(\mathrm{N}, \mathrm{E}, \mathrm{S}, \mathrm{W})$. The whole investigation area was described as very diverse.

On December 26th 2011 the southern part of Norway was affected by the storm Dagmar that caused several forest damages along Norway's west coast. This paper describes how those forest patches were detected using a Landsat time series and change detection. The very diverse terrain was considered to be very challenging.

The study investigated the applicability of freely available satellite data for detecting storm damages in spruce forests. It was investigated, which vegetation indices were most significant for obtaining a good detection result of changes in spruce forests. Further, based on the most suitable index, a semi-automatic detection model was built. A very crucial process step was the pre-processing of the Landsat scenes in order to make them comparable, taking into account how diverse and rough the landscape was. Because of the outsourced preprocessing, the detection model was called semi-automatic. The pre-processing still needs to be done separately because it requires too many independent specifications (Which acquisition date? Which atmospheric correction? Which DEM is available? etc.). As the final output a raster map, classified into different damage categories, was provided to the end user. Skog og Landskap, as well as the local forest administration will later benefit from this study, because the time demanding step of searching for and detecting storm damages in each single forest district can be done within just a few hours.

\section{Input Data and Data Processing}

\subsection{Landsat ETM+}

From USGS.earthexplorer.gov two Landsat scenes were downloaded. Both had a one year time difference in order to ensure equal conditions of plant phenology. The data acquisitions were 8th of October 2011 and $24^{\text {th }}$ of September 2012. Both images had a cloud cover between $25 \%$ and $40 \%$, but even though the cloud cover was comparatively high, the investigated communes were cloud free. Both Landsat scenes were under influence of SLC-off. The commune Stryn still was affected by the inner phase-out of black lines, and both Landsat scenes were 'L1T' products. The 'Standard Terrain Correction' included radiometric and geometric correction via GLS2000. Further, the satellite data was provided in UTM_WGS84_zone31N. The whole Landsat extent did cover areas for UTM WGS84_zone31N and UTM_WGS84_zone32N, but after clipping the satellite data to the commune's rectangular extent, a projection to UTM_WGS84_zone32N (EPSG code: 32632) was executed. 


\subsection{Digital Elevation Model}

'Skog og Landskap' (Norwegian Forest and Landscape Institute) provided Digital Terrain Elevation Data (DTED10) with a resolution of 10 by $10 \mathrm{~m}$, produced from vector line data of altitude lines that were converted to a raster dataset. The altitude lines were derived from stereo photogrammetry from aerial imagery, i.e. the Norwegian 'AR5' land cover map. The DTED10 was necessary for applying topographic correction.

\subsection{Storm Disturbance Areas}

A dataset containing forest storm damage areas served as ground truth data. This dataset was in vector format, including several polygons of known damaged areas. For each polygon, an attribute table-entry with actual damage percentage of the forest patch was attached. The dataset was produced by Torkel Hofseth, the county forester of all communes. Together with the local forester of the Stryn commune, Asle Lyslo, who had been administrating the windstorm logging processes, the storm areas were mapped and digitized. Further to the damage mapping, damage percentage classes were attached $(0-100 \%$ damage in $10 \%$ steps).

\subsection{Forest Stand Data and Harvest Information}

The forest county administration provided a shape file with all spruce and pine forest stands of the communes Stryn, Gloppen and Sogndal. All spruce stands were extracted from this dataset. The purpose of this dataset was to function as a clip mask in the semi-automatic detection model. To verify if and when a forest stand had been cleared after the storm event, information about every single stand's clearing date for all three communes were considered.

\subsection{Vegetation Indices}

Vegetation indices offer the possibility of deriving certain, specific information about the environment from remotely sensed data, which are not clearly distinguishable or nonvisible from a simple multispectral satellite image. Using defined bands and algorithms they support environmental monitoring in various aspects, for example in distinguishing vegetation, vegetation- or soil moisture, and so on.

\subsection{The Wide Dynamic Range Vegetation Index}

The Wide Dynamic Range Vegetation Index was an enhancement of the NDVI. Reducing the NIR band by a certain $\alpha$-factor, the contrast in comparison with the NDVI was increased. This made differences in vegetation more visible. An investigation by Geoffrey et al. (2004) suggested a factor load $\alpha$ of 0.28 to increase the visible range over the NDVI of $33 \%$. (GEOFFREY et al. 2004). The same $\alpha$ value was applied in this study.

$$
W D R V I=\frac{\left(\alpha * \rho_{0.835}-\rho_{0.660}\right)}{\left(\alpha * \rho_{0.835}+\rho_{0.660}\right)}
$$




\section{Methodology}

\subsection{Data Pre-processing}

To improve the image quality, 'haze reduction' was first applied. This radiometric correction was "based on a 'tasselled cap transformation', removing a haze correlating component from multispectral images" (ATCOR3 2013). As result a less blurry, more contrast full image was produced.

When investigating two images in change detection, it was required to perfectly match each pixel's location in both images to each other. A misregistration of 1 pixel could have led to result errors of $50 \%$ and to $10 \%$ for 0.2 pixels (TOWNSHEND et al. 1992). The co-registration tool 'AutoSync' in ERDAS used one image as master on which a second image was rectified. It automatically set ground control points in the master image and found those ground control points in the slave image based on a certain probability threshold. To achieve the highest possible accuracy, the panchromatic band with a resolution of $15 \mathrm{~m}$ was used for co-registering the images. AutoSync used 101 GCP's, 'affine' as geometrical model type for adjustment with a RMS (Root Mean Square) threshold of 0.5 and corrected an RMS error of 0.004232 , which equalled $12.7 \mathrm{~cm}$.

Since the investigation area covered a very diverse terrain with slope inclinations between $5^{\circ}$ and $45^{\circ}$, and slope orientations in all directions, a basic atmospheric correction (like Dark Object Subtraction, COST or even ATCOR2) couldn't improve the image quality in a way that would have made the scenes comparable. ATCOR3, a built-in tool in ERDAS, was applied to correct atmospheric and topographic effects. This step required information about sun zenith and azimuth, calculated from acquisition date, time, and latitude/longitude of the scene centre, and information derived from a DEM (Digital Elevation Model with 10 $\mathrm{m}$ resolution) for estimating slope, aspect, skyview, and shadow. Within ATCOR3, GUI specifications for 'used sensor settings' were required, in this case for Landsat 7 ETM+ with the calibration file '17_etm_template.cal'. Besides those specifications, 'atmospheric selections' were set. Here the required scene visibility was automatically estimated with 59 $\mathrm{km}$. For 'aersoltype', the 'model for solar region' was set to 'rural', 'fall_(spring)_rural', and the 'model for thermal region' to 'fall'. After executing ATCOR3, the resulting image showed an absolute shadow removal, contrast (and thereby information) improvement, and created an image without quality decreasing environmental and topographical influences (such as shadows caused by mountain peaks). It must be mentioned, that for certain areas, where the shadow influence was too high, reflectance information couldn't be restored (For band combination false infrared this was visible as single bright green pixel). Those smallpatched areas appeared clearly different, compared to the expected pre-processed image outcomes, but didn't influence the investigation areas.

\subsection{Change Detection}

After calculating the WDRVI on the pre-processed data, the whole concept of analysing the index was based on change detection. Generally speaking, this was "the process of identifying differences in the state of an object or phenomenon by observing at different times" (BHAGAT 2012). 'Vegetation index differencing', a very simple, straightforward approach, was used as the change detection method. Calculating the difference image was 
done by subtracting the 'later date' image from the previous one. The results had both positive and negative values. Taking the NDVI as an example, it generally could be interpreted as a vegetation increase for negative values and a decrease in vegetation for positive values. Change results of zero indicated no changes. (NORDBERG et al. 2005)

\subsection{Threshold Extraction}

All pixel values intersecting with the storm damage data were extracted and plotted. Considering a certain variety in the data, caused by outliers and extreme values, a general increasing trend was already recognizable in the boxplot (see Fig. 1).

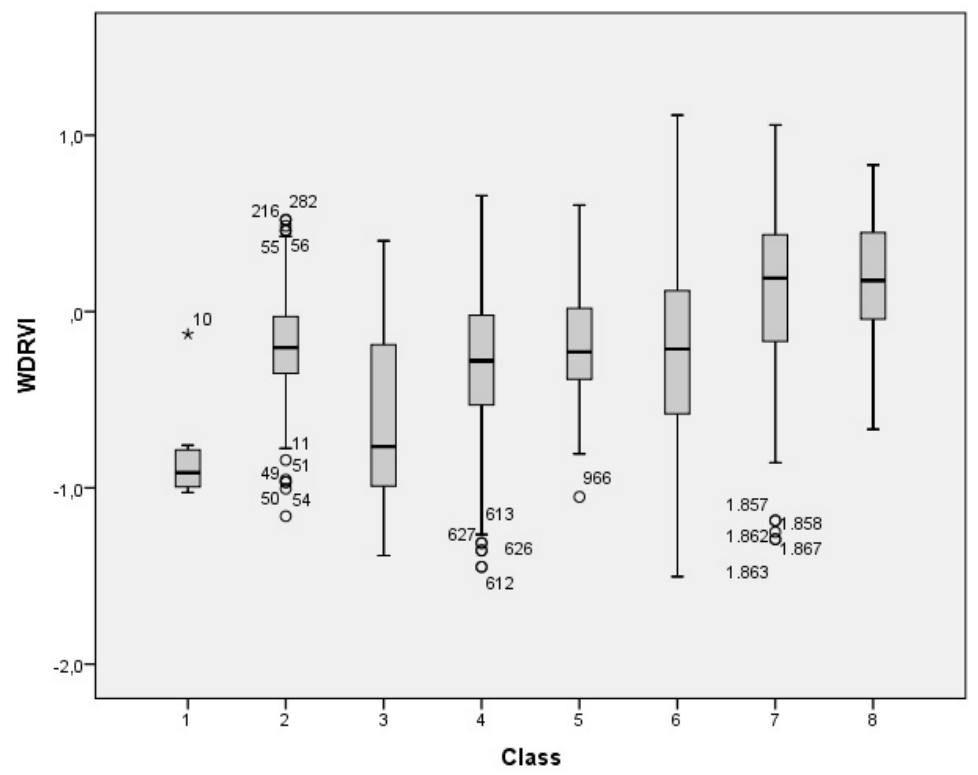

Fig. 1: Boxplot of dWDRVI for each damage class in $10 \%$ steps

In order to set boundaries for different damage classes based on the high peak of the data, the $95 \%$ quantile was applied to exclude extreme values and false pixels from the change index.

To derive WDRVI change detection thresholds for certain damage classes, a non-linear regression analysis was first applied. The closest fit was achieved with an exponential function. This function represented the general data trend, and was fairly good with a root mean square error of 0.0755 . The derived function was intersected into three parts, using the partitioning around medoids classification. The intersections represented damage class intervals (low, medium and severe damage). The derived thresholds were entered in a spatial model, developed with the ERDAS 2013 Spatial Modeler. 


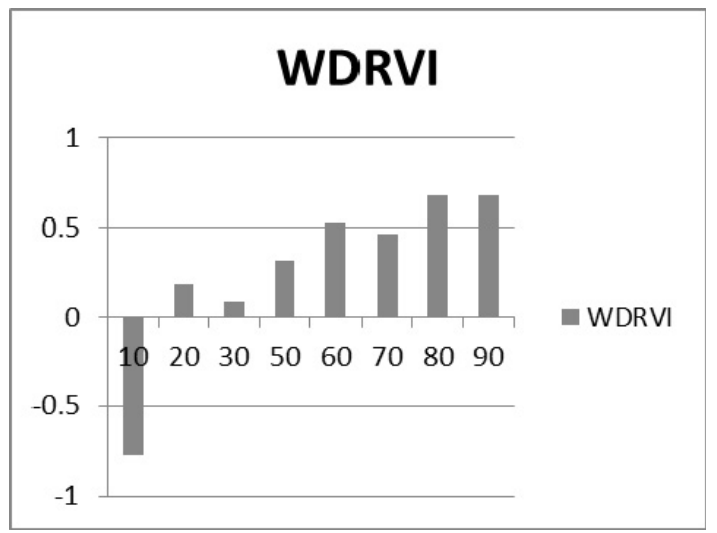

Fig. 2: dWDRVI - Quantile (95\%) for each damage class

\section{Results}

The thresholds, which serve as boundaries for each class are derived from one large training area, including several (more than 100) damage patches distributed over one commune. Applying the thresholds in the same study area on three communes achieved high detection accuracies of $96 \%$. The estimated thresholds represented damage classes between $20 \%$ and $43 \%$ (low damage), $43 \%$ to $68 \%$ (medium damage), and $68 \%$ to $100 \%$ (severe damage). Table 1 shows which WDRVI change detection values described each damage class' boundaries.

The whole process chain of the semi-automatic detection model combined the index calculation, the change detection, a clip function to mask out all forest areas, and the threshold application, to extract possibly damaged areas (see Fig. 3). The model creates a raster data set, which is classified into three categories, and shows the damaged areas, as seen in Fig. 4.

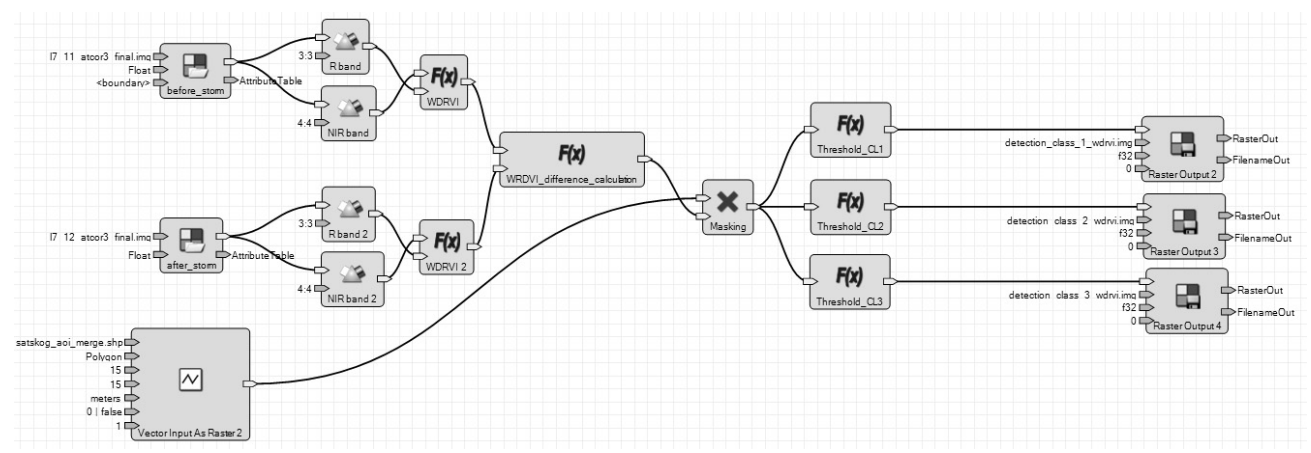

Fig. 3: Semi automatic forest storm damage detection model in ERDAS 2013 'Spatial Modeler' 
Table 1: dWDRVI Class thresholds after non-linear regression analysis and partitioning around medoids classification

\begin{tabular}{|l|l|l|l|l|}
\hline Class & THR low & THR high & dam \% low & dam \% high \\
\hline 1 & 0.044 & 0.292 & 20 & 43.26 \\
\hline 2 & 0.293 & 0.536 & 43.27 & 68.83 \\
\hline 3 & 0.537 & 0.738 & 68.84 & 100 \\
\hline
\end{tabular}

\section{Detection Results of first $\mathrm{AOI}$}

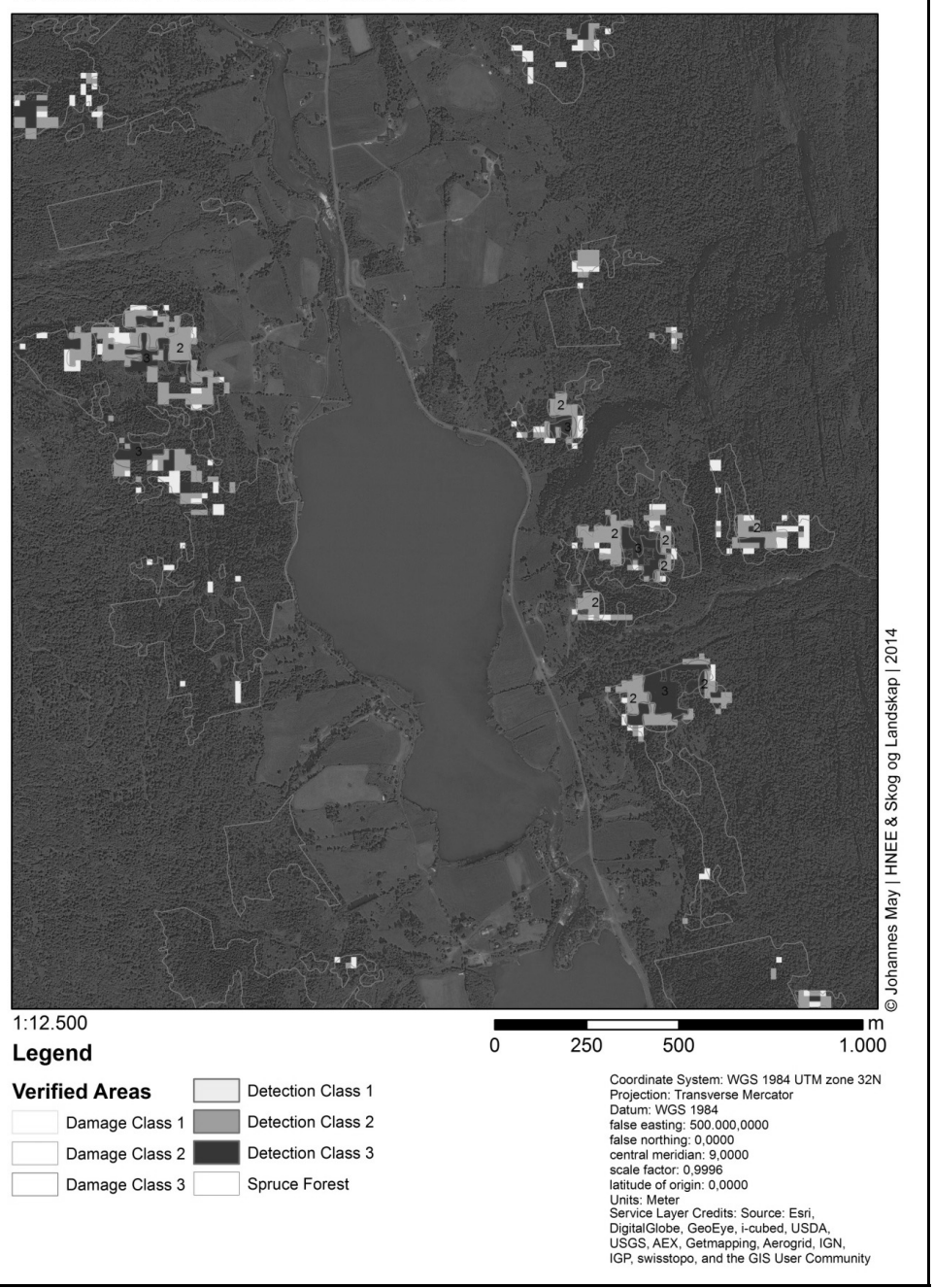

Fig. 4: Example of detection results, with aerial imagery in the background; numbers within the colored areas represent the damage class of the ground truth data set 
108 detected areas were chosen and verified in a field verification process. They provided the basis of how accurate the semi automatic detection algorithm worked. The final accuracy assessment based on this process resulted in an overall accuracy of $96.3 \%$ and Cohen's Kappa of 0.94 (Table 2), which were very good and highly accurate outcomes.

Table 2: Accuracy Assessment after Field Verification of Detection Results

\begin{tabular}{|c|c|c|c|c|}
\hline Classification & Class 1 & Class 2 & Class 3 & Row Total \\
\hline Class 1 & 26 & 0 & 0 & 26 \\
\hline Class 2 & 0 & 48 & 0 & 48 \\
\hline Class 3 & 0 & 0 & 30 & 30 \\
\hline Column Total & 29 & 49 & 30 & 108 \\
\hline
\end{tabular}

Overall Accuracy $96.30 \%$

Cohen's KAPPA $\quad 0.94$

\section{Conclusion and Outlook}

For applying an analysis based on a change detection, which compares two images that cover the same location at a different time, most attention must be placed on precise data pre-processing. This data normalization is the key element in a possible operational application of this model, to increase the detection accuracy and reliability. However, this study was performed to investigate the feasibility of a detection of storm damages in spruce forests. The results were very promising, but applying this semi-automated detection model to different Landsat Scenes and Sensors (Landsat 8 operates without black lines in the image, like found for Landsat 7), different forest types, and tree species, is recommended to make the model more robust. A following, scheduled study will investigate more areas, and provide a fully open source operating Python script.

\section{References}

ATCOR3 (2013), ATCOR FOR IMAGINE 2013, Haze Reduction, Atmospheric and Topographic Correction. GEOSYSTEMS GmbH, Model ATCOR3 for Rugged Terrain, p. 28.

Baumann, M., Ozdogan, M., Wolter, P. T., Krylov, A., Vladimirova, N. \& RADELOFF, V. C. (2013), Landsat remote sensing of forest windfall disturbance. Remote Sensing of Environment, 143, 171-179.

Bhagat, V. S. (2012), Use of Remote Sensing Techniques for Robust Digital Change Detection of Land: A Review. Recent Patents on Space Technology, 2 (2). 
Carvalho, D. F. De, Durigon, V. L., Antunes, M. A. H., De Almeida, W. S. \& De OliveIRA, P. T. S. (2014), Predicting soil erosion using Rusle and NDVI time series from TM Landsat 5. Pesq. agropec. bras., Brasília, 49 (3), 215-224.

Geoffrey, M. H., ViñA, A. \& Gitelson, A. (2004), The Wide Dynamic Range Vegetation Index and its Potential Utility for Gap Analysis. Center for Advanced Land Management Information Technologies (CALMIT), School of Natural Resources, University of Nebraska-Lincoln, 55-56.

King, D. J., Olthof, I., PellikKa, P. K. E., Seed, E. D. \& Butson, C. (2004), Modelling and Mapping Damage to Forests from an Ice Storm Using Remote Sensing and Environmental Data. Natural Hazards, 35, 321-342.

Lausch, A., Heurich, M., Gordalla, D., Dobner, H.-J., Gwillym-Margianto, S. \& SALBACH, C. (2013), Forecasting potential bark beetle outbreaks based on spruce forest vitality using hyperspectral remote-sensing techniques at different scales. Forest Ecology and Management, 308, 76-89.

NordBerG, M.-L. \& Evertson, J. (2005), Vegetation Index Differencing and Linear Regression for Change Detection in a Swedish Mountain Range Using Landsat TM and ETM+ Imagery. Land Degradation and Development, 16.

Pradhan, B., Suliman, M. D. H. B. \& Awang, M. A. B. (2007), Forest fire susceptibility and risk mapping using remote sensing and geographical information system (GIS). Emerald, 16 (3).

Townshend, J. R. G., Justice, C. O., Gurney, C. \& McManus, J. (1992), The Impact of Misregistration on Change Detection. Institute of Electrical and Electronics Engineers (IEEE), 30 (5), 1058-1059. 